\title{
Study of deviant use of international non-proprietary name of medicines in India
}

\author{
Rangeel Singh Raina
}

Associate Professor, Dept. of Pharmacology, Government Doon Medical College, Dehradun, Uttrakhand, India

Corresponding Author:

Email: rainarangeel@gmail.com

\begin{abstract}
Introduction: International Nonproprietary Names (INNs) are internationally documented names for medicines recommended by the World Health Organization (WHO) and provide a standardized system of nomenclature.

Objective: To analyse the current pattern of use of INNs by different pharmaceuticals companies in India.

Methodology: The relevant material was systemically collated and analysed after collecting material from websites of WHO, pharmaceutical companies, MIMS and CIMS. We then analysed what is the severity of misuse of INNs in India and categorize the gaps and loopholes at the different level.

Results: It has been found that for implementation of INN, most important problem lies in the policy regime along with and deficient coordination in between drug authorities in India. Both big and small pharmaceutical companies were involved in the misuse (10-40\%) of INNs. Number of INN stems have been exploited by different companies. Most commonly used INN were by "-grel", followed by "-pril "-pride" and "gli-".

A great number of cases of misuse of INNs in our country involve drugs for cardiac, renal diseases, and diabetes. Although drug authority has issued INN protection letter by WHO to few pharmaceutical companies but in spite of that number of brand names are still derived from INN.

Conclusion: Many lacunae exist in the INN implementation in India. It is essential to develop improved coordination, specific mandate and suitable policy to safeguard INNs in India.
\end{abstract}

Keywords: Brand name, Generic, Propriety name.

\section{Introduction}

Mostly medicines are usually marketed and promoted under brand names. However, to harmonize and suitable international trade of drug, World Health Organization (WHO) list of essential medicines was prepared, and for exchanges and scientific research related to drugs, generic name has been established. ${ }^{1}$

Several efforts have been initiated to utilize only generic names for the trade of drugs. Governments were already advised to encourage the use of generic names and prevent the use of brand names. This cost effective exercise will facilitate consumers to choose from several sources of the same pharmaceutical substance. In this regard, WHO has introduced an international generic nomenclature system called International Nonproprietary Names (INNs). This step has been commenced to avoid the confusion in drug nomenclature at the global level and ensure medicine safety for consumers. ${ }^{2}$

The World Health Assembly (WHA), called upon to take necessary steps to control the use and misuse of INNs. WHA has instructed to all pharmaceutical companies to discourage the use of names derived from INN stems as trademarks. Later on in 1949, WHO expert committee prepared a general rules of nomenclature to unify the pharmacopoeias. After adopting in 1950 by resolution 3.11 of the WHA, the first list of INNs was formally published by WHO In 1953. In 1993, WHA adopted resolution 46.19 exhorting member states to formulate appropriate rules and regulations for the use of INNs.
Generally, an INN has two parts- a randomly selected, fancy term and a stem. ${ }^{3}$ Stems usually indicate the relationship between two pharmaceutical materials using a common element or compound. For example, the INN propranolol comprises the stem-olol and the fancy term propra.

The rationality behind the use of common stems in the selection of INNs was to avoid the confusion among nomenclature of generic drugs. Initially shortened chemical names were used as generic names but this system was found to be very limited, as many molecules have similar elements and groups such as methyl or benzene rings in their chemical structures. ${ }^{4}$ Hence, it looked like to be rationale to develop names that helped to identify such common substances and groups. This rationale led to the use of common stems in the selection of INNs.

The selection process is initiated through an application proposing an INN for a new pharmaceutical substance by its manufacturer or inventor. Generally, the applicant has to suggest three possible names to be recommended as an INN.

The selection process has the four stages as depicted in diagram: ${ }^{5}$ 


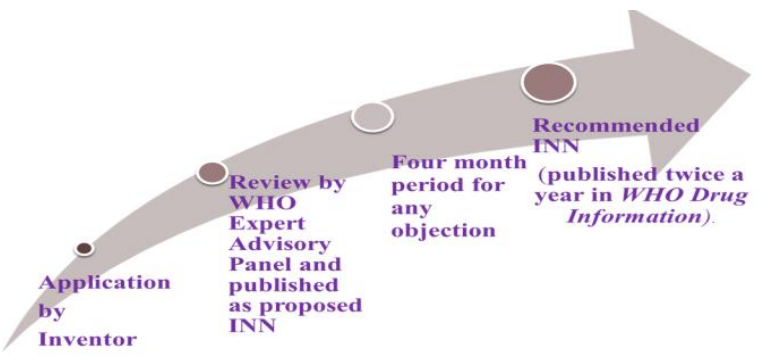

Usually, if a person has discovered or developed a name then the marketing a pharmaceutical substance by that name will be accepted. ${ }^{6}$

In our country, the trademark registration of words that are declared as INNs or misleadingly similar to INNs is prohibited under Section 13 (b) of the Trade Marks Act, 1999. Furthermore, it is also not mandatory to register a trademark in India and a mark could be protected as an unregistered trademark as even without registration. In spite of this section, there are numerous example in India where companies have brand names that have been derived from INNs and even registered as trademarks.

To overcome and control this problemt, WHO has issued INN protection letters to the Drugs Controller General of India (DCGI) appealing the DCGI to take an suitable action to discourage the trademark registration of such names. So it emphasizes that $t$ there are major gaps in the legal and policy regime in India on the use of INNs. ${ }^{7}$
This study is designed to assess some of these problems and pattern of use of INN by different pharmaceuticals companies in India.

\section{Aims and Objective}

1. To analyse the current status of pattern of use of INNs by different pharmaceuticals companies in India.

2. To identifies the gaps and loophole at the level of different stakeholders.

\section{Methodology}

The data was collected from different sources like website of WHO, sites of pharmaceutical companies, drug informative sources like, drug today, MIMS and CIMS. Then collected data was systemically collated and analysed. We also then analysed how much success has been achieved in controlling the misuse of INNs in India by different measures adopted by drug authority.

\section{Results}

It has been observed by the different results that there are major faults in the regulation of misuse of INN and there is lack of coordination in between drug authorities in India with state authorities. Both, big and small pharmaceutical companies were involved in the misuse (10-40\%) of INNs. (Table 1) It was also observed that even without a registration, a trademark may have protection and there is no compulsion to register a trademark.

Table 1: Names taken up from INNs by different pharmaceutical companies in India

\begin{tabular}{|l|c|c|c|c|}
\hline S. No. & INN & Stem & Brand name & Company name \\
\hline 1 & Ramipril & pril & Codiopril & Dr. Reddy's \\
\hline 2 & levetiracetam & acetam & levesam & Nicholas Piramal \\
\hline 3 & Glimepiride & gli & Glimer & Nicholas Piramal \\
\hline 4 & Tizanidine & -nidine & Tizan & Sun Pharmaceuticals \\
\hline 5 & Alprazolam & -azolam & Alzolam & Sun Pharmaceuticals \\
\hline 6 & Chloroquine & Quine & Uquine Injection & Alkem \\
\hline 7 & Sertraline & Sert- & Xsert & Cadila Pharmaceuticals \\
\hline 8 & Zidovudine - & Vudine & Zidovir & Cipla \\
\hline 9 & Vinleurosine & Osine & Virosine DR & Ranbaxy \\
\hline
\end{tabular}

In such a vast and fragmented market of India, it has been found that INN is frequently coined by some of the leading companies in India. Data has showed that some leading pharmaceuticals Company of India like Sun pharmaceuticals, Ranbaxy, Nicolas piramal, Lupin ltd have been indulged in misuse of INN in their brand names. These pharmaceutical companies in India have promoted their product under brand names which are very much alike to INNs and some have even utilized INN stems. (Table 2)

Table 2: INN coined by leading companies in India

\begin{tabular}{|l|c|c|}
\hline \multicolumn{1}{|c|}{ Company } & No of brand surveyed & No of brands derived from INNs \\
\hline Ranbaxy & 184 & 8 \\
\hline Cipla & 97 & 17 \\
\hline Dr Reddy's labs & 189 & 15 \\
\hline Sun pharmaceuticals & 400 & 90 \\
\hline Nicolas piramal & 156 & 56 \\
\hline Lupin ltd & 150 & 20 \\
\hline Cadila & 78 & 24 \\
\hline
\end{tabular}


In India, there are number of pharmaceutical products with brand names which are apparently derived from INNs. Both large and small scale industries, including multinational companies, are involved in the same practice. It has been observed that number of pharmaceutical companies have exploited. Most commonly used INN were by “-grel”, followed by "-pril "-pride" and "gli-". (Fig. 1) Whereas "-pril" and "-olol" are stems for cardiovascular drugs, "-prazole" is a stem used for proton pump inhibitors, "grel-" is a stem for antiplatelet drugs, while "-platin" is stem for oncology drugs.

\section{Fig. 1: Commonly misused INN stems}

It has been found from collected data that most of the national and multinational companies are involved in misuse of INNs for the drugs used for cardiac diseases, GIT related diseases and diabetes.
In this regard to curb the misappropriation of INN WHO has instructed to the Drugs Controller General of India (DCGI) to take suitable measures against misuse of INN by issuing protection letters, but there is no any evidence of appropriate remedial action so far (Fig. 2)

\begin{tabular}{|l|l|l|l|l|}
\hline INN & Stem & TM & $\begin{array}{l}\text { TM } \\
\text { number }\end{array}$ & Firm \\
\hline NA* $^{*}$ & cef & Cef & B1096796 & Mica Labs Pvt Ltd, Ranchi \\
\hline glimepiride & gli & Gliride & B1027541 & Varun Continental, Mumbai \\
\hline glimepiride & gli & Glimeride & B965893 & Medley Pharms, Mumbai \\
\hline glimepiride & gli & Glime & 987850 & $\begin{array}{l}\text { Biochem Pharms. Industries, } \\
\text { Mumbai }\end{array}$ \\
\hline glimepiride & gli & Glimerit & B1056868 & Aviat Chemical Private Ltd, \\
\hline & gli & Gliride & 955139 & Nicholas Piramal India, Mumbai \\
\hline clopidogrel & grel & Pidogrel & 937874 & Aviat Chem., Mumbai \\
\hline clopidogrel & grel & Clogrel & 905979 & Cadila Health Care, Ahmedabad \\
\hline clopidogrel & grel & Clopigrel & 1095907 & USV, Mumbai \\
\hline & grel & C-Grel & 1085860 & Medisearch Pharm., Chennai \\
\hline & grel & Idogrel & 1136886 & Rajvi Vipul Bhagat, Mumbai \\
\hline
\end{tabular}

\section{Fig. 2: Protection letters issued to DCGI by who}

It has also been observed that so far DCGI has not formulated any precise mandate to regulate the use of INNs in India. As DCGI is the nodal agency representing India to WHO, so there should be a effective mandate supported with appropriate polices and regulations, so that regulation can be strictly implicable. Although, the drugs and cosmetics rules, 1945 demands that the printing of generic names should be prominent and double the font size of brand names, however, this prerequisite is often ignored and the brand name is usually printed in bold letters and 
attractive colours. So a stringent action should be taken for the implementation of the rules. ${ }^{8}$

\section{Discussion}

Although there are rules to restrict the misuse of stem derived from INN, in spite of that, there are number of examples in India where brand names are wholly or partially being derived from INNs.

The pharmaceutical industry in India positions fourth in the world in terms of volume whereas, they ranked thirteenth in terms of value. So Indian pharma industries have important role in global pharmaceutical industry. ${ }^{9}$

It is need of the hour that trade mark office should have better harmonization with the central and state drug regulatory authorities for the use and protection of INNs. This problem of exploitation of INN might be improved by the centralization of drug regulatory system with active control on state DRA.

As per the WHO guidelines, a proper INN reporting and monitoring system should be established and details of the actions taken by the DCGI in response to WHO letters should be well-versed to WHO. A database of brand names registered throughout the country should be maintained and displayed in public domain on internet. There is urgent need to create awareness about the misuse of INNs. Medical and legal professionals should be sensitized to this issue.

\section{Conclusions}

International nonproprietary names are distinctive names formulated to identify the complex chemical compositions of pharmaceutical substances. In our country, many lacunae exist in the INN implementation in India. It is essential to develop improved coordination, specific mandate and suitable policy guidelines to shield INNs in India. There is a ominous need to generate awareness about misuse of INN by pharmaceutical industry and to sensitize the severity of problem to Medical and legal experts.

\section{References}

1. Anant Phadke, "Profiteering in the Pharmaceutical Sector", Info Change News \& Features, July 2005 [online], available at http://www.infochangeindia.org/analysis78.jsp, visited on 28th February 2006.

2. International Non-proprietary Names [online], available at http://www. amaassn.org/ama1/pub/upload/mm/365/timeprocessrqrd_090 2.doc

3. Geoffrey Sampson; Paul Martin Postal (2005). The 'language instinct' debate. Continuum International Publishing Group. p. 124. ISBN 978-0-8264-7385-1. Retrieved 2009-07-21.

4. AMA, International Nonproprietary Names, [online] available at www.amaassn.org/ama1/pub/ upload/mm/365/timeprocessrqrd_090 2.doc, visited on 13th march.
5. WHO, Guidelines on the Use of International Nonproprietary Names (INNs) for Pharmaceutical Substances. (Geneva: World Health Organization, 1997), p.13.

6. WHO, Procedure for the Selection of Recommended International Nonproprietary Names for Pharmaceutical Substances, text adopted by Executive Board of WHO in Resolution EB 15.R7, 1955 and amended by Resolution EB 43.R9, 1969, Article 2, reprinted in WHO Drug Information, vol.19, no.2, 2005, pp.189-90.)

7. P. Narayanan, Law of Trade Marks and Passing off, (Kolkata: Eastern Law House, 2004) edn.6, p.253.

8. Annual Report, 2002-2003, of the Controller Gereral of Patents, Designs, Trade Marks and Geographical Indications, pp.58, 63.

9. Piribo, Indian Pharmaceutical Industry. Issues and Opportunities, [online] available at http://www.pribro.com/publications/country/indian_phar ma_issues.html, visited on 14th March 2008. 